\title{
Continuous Dopaminergic Stimulation in Parkinson's Disease
}

\author{
J.A. Obeso, M.R. Luquin, J. Vaamonde, F. Grandas and J.M. Martinez Lage
}

\begin{abstract}
Complex motor fluctuations and dyskinesias ("on-off" phenomenon) in Parkinson's disease can be corrected by parenteral administration of levodopa, levodopa-methyl-ester, lisuride and apomorphine. Levodopa and levodopa-methyl-ester may only be administered intravenously because of their low solubility. Lisuride and apomorphine are readily absorbed after subcutaneous administration. Repeated or continuous intravenous infusions of levodopa have been given for a few days, using a wearable "jacket-like" pump, with good results. So far, lisuride is the only dopamine agonist used for chronic treatment by continuous infusion. The "on-off" effect is adequately controlled in most patients by subcutaneous lisuride administration (plus oral levodopa). However, adverse effects, particularly psychiatric complications, constitute a major limiting factor for routine applications of this form of treatment. Subcutaneous apomorphine infusion is unlikely to become a standard therapeutic procedure in Parkinson's disease, but it is a very valuable research method to gain further insight into the pathophysiology of motor fluctuations in Parkinson's disease.
\end{abstract}

RÉSUMÉ: Stimulation dopaminergique continue dans la maladie de Parkinson. Les fluctuations motrices complexes et les dyskinésies (phénomène du "on-off") dans la maladie de Parkinson peuvent être corrigées par l'administration parentérale de lévodopa, de lévodopa-méthyl-ester, de lisuride et d'apomorphine. La lévodopa et la lévodopa-méthylester ne peuvent être administrées que par voie intraveineuse à cause de leur faible solubilité. Le lisuride et l'apomorphine sont absorbés facilement lorsqu'ils sont administrés par voie sous-cutanée. Des perfusions intraveineuses répétées ou continues de lévodopa, administrées pendant quelques jours au moyen d'une pompe portée comme une veste, ont donné de bons résultats. Jusqu'à maintenant, le lisuride est le seul agoniste dopaminergique utilisé dans le traitement par perfusion continue à long terme. L'effet "on-off" est contrôlé adéquatement chez la plupart des patients par l'administration sous-cutanée de lisuride (en plus de la lévodopa). Cependant, les effets secondaires, particulièrement les complications psychiatriques, sont un facteur limitant important dans l'application courante de cette forme de traitement. Il est peu probable que la perfusion sous-cutanée d'apomorphine devienne une pratique thérapeutique courante dans la maladie de Parkinson, mais elle constitue une méthode de recherche précieuse pour acquérir de nouvelles connaissances sur la pathophysiologie des fluctuations motrices dans la maladie de Parkinson.

Can. J. Neurol. Sci. 1987; 14:488-492

Levodopa plus a peripheral dopa decarboxylase inhibitor (DDI) remains the mainstay treatment of Parkinson's disease.

After several years of treatment, an important proportion of patients, who have initially shown excellent response to levodopa, develop motor complications.' Daily fluctuations in motor performance, frequently accompanied by dyskinesias, are the most common problem encountered after long-term levodopa therapy. The treatment of complex motor fluctuations in Parkinson's disease is a major clinical challenge and a very difficult problem to resolve or avoid with conventional therapeutic strategies. $^{2}$

Both pharmacokinetic and pharmacodynamic factors are probably involved in the origin of motor fluctuations in patients chronically treated with levodopa. ${ }^{3,4}$ Variables conditioning levodopa absorption and its intracerebral biodisponibility which have been so far identified as contributing to "on-off' fluctuations include: slow dissolution of the levodopa tablet in the stomach, ${ }^{5}$ delayed gastric emptying, ${ }^{6}$ interference with intestinal absorption of levodopa due to competition with aminoacids from the diet ${ }^{7}$ competition with the same neutral amino acids for transport from plasma to brain, ${ }^{8}$ and inhibition of the active transport mechanism by 3-O-methyldopa accumulation when large doses of levodopa plus DDI are used. ${ }^{9,10}$ Central factors such as decreased capacity to store dopamine and desensitization of postsynaptic striatal dopaminergic receptors as a consequence of chronic dopamine stimulation may also be contributing to the origin of motor fluctuations in Parkinson's disease. ${ }^{3,4}$

In this paper we shall discuss the present possibilities of improving motor functions in Parkinson's disease by continuous infusion of antiparkinsonian drugs via parenteral route. 
The technical aspects of drug delivery systems available for the treatment of Parkinson's disease have been discussed elsewhere. ${ }^{11,12}$

\section{Intravenous levodopa}

The therapeutic applications of levodopa infusion in Parkinson's disease was first considered by Shoulson et al in $1975 .{ }^{13}$ They showed a remarkably good response to intravenous levodopa in five patients with "wearing off" phenomenon, but the response was not maintained when the patients were asked to stand up and the method was abandoned in favour of new dopamine agonists. In 1979 Rosin et a ${ }^{14}$ treated with intravenous levodopa for 7 days a severe parkinsonian patient who had had an abdominal operation. His response to treatment was however not constant during that period. Interest in the intravenous administration of levodopa reappeared recently when three independent groups showed that severe "on-off" fluctuations could be virtually abolished during many consecutive hours. Quinn et al ${ }^{15}$ reported a dramatic improvement of "on-off" swings in 10 patients, who remained independent during the infusions. These findings were confirmed by Hardie et al ${ }^{16}$ and Nutt et a ${ }^{17}$ who studied 12 and 6 severe patients respectively. In addition, Nutt et $\mathrm{al}^{17}$ showed that despite maintaining constant plasma levodopa levels, "off" periods could supervene following a high protein meal or the oral administration of phenylalamine, leucine or isoleucine. This was explained as competition between large neutral amino acids and levodopa for transport from plasma to brain. These studies also suggest a certain difficulty in keeping a stable response for longer than $\mathbf{4 8}$ hours in some patients. Alternatively, Marion et $\mathrm{al}^{18}$ gave intravenous infusions of levodopa to three subjects on five consecutive days, each session lasting 6 hours on day 1 , and 12 hours on days 2 to 5 . Although two patients experienced some transient "off' episodes, all enjoyed a better clinical control during the infusion than on chronic oral levodopa treatment. Chase et a ${ }^{19}$ obtained excellent results in patients with "wearing off", but reported more difficulty in controlling the "on-off" phenomenon when using continuous infusions of levodopa for 11 consecutive days. Improvement in motor function occurred at different rates for patients with "wearing off" and "on-off" fluctuations. The time required to reduce motor fluctuations by $50 \%$ averaged 3.9 days in patients with "wearing-off" and 8 days in those with "on-off", the latter group never achieving complete stabilization despite maintaining constant levodopa plasma levels. ${ }^{19}$

Although all these studies with intravenous levodopa coincide in showing a marked benefit of this form of treatment, a number of problems limit the practical application of levodopa in continuous infusion. First, the high acidity and low solubility of levodopa necessitates its dilution in large volumes, which in turn causes some difficulties with the size of the pump refilling procedure, etc. Secondly, intravenous delivery of levodopa does not remove the competition of neutral amino acids for transport across the blood brain barrier nor the possible adverse effect on motor function of 3-OM-dopa accumulation following high levodopa intake. ${ }^{9,10,20}$ Lastly, the price of levodopa solutions for intravenous administration is probably too high to be used widely.

\section{Levodopa-methyl ester}

Levodopa-methyl ester is very soluble and can have the same therapeutic effect as levodopa itself. ${ }^{19,21}$ However, it has all the other limitations mentioned above for levodopa. In addition, levodopa-methyl ester is metabolized into alcoholic compounds which could potentially be toxic to the organism.

\section{Lisuride}

The high solubility of lisuride in saline allows its administration by intravenous or subcutaneous route in small volumes. We reported the sustained antiparkinsonian effect of lisuride when given by intravenous infusion over a period of 8 to 72 hours (Figure 1). ${ }^{22.23}$ However, in about $20 \%$ of patients there was no positive effect what soever ${ }^{24}$ (Figure 2). Tolerance was usually acceptable by giving a bolus of $40 \mathrm{mg}$ of domperidone (IV) 30 minutes before initiation of the infusion. Although it is now recognized that acute intravenous lisuride infusion added to standard oral levodopa plus DDI may not be effective in correcting motor fluctuations, we showed a sustained antiparkinsonian effect of continuous lisuride infusion over many months. ${ }^{25}$

Up to date we have studied 30 patients with long-standing Parkinson's disease, and severe motor disability associated with chronic levodopa therapy, who were unresponsive to treatment with standard antiparkinsonian drugs. Four patients abandoned the trial in the first four weeks due to psychiatric complications in two, inability to use the system at home in one and development of local nodules as well as rejection of permanent dependence upon the pump in the fourth case. In the 26

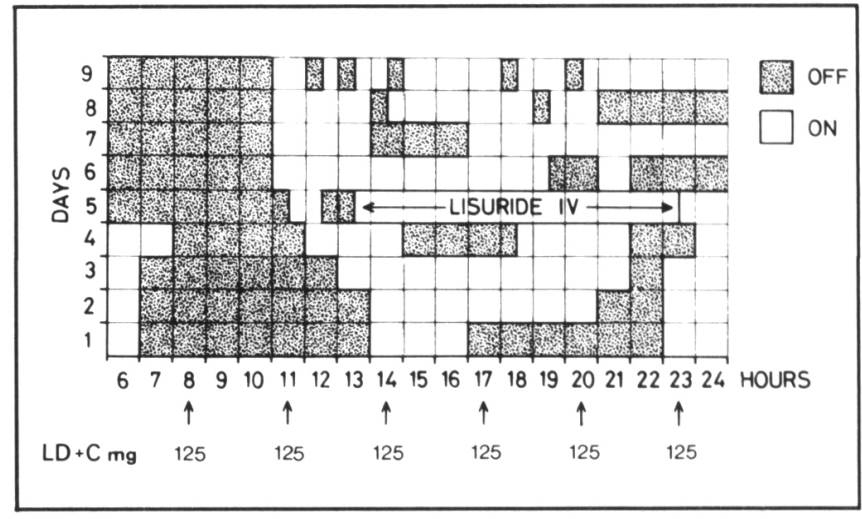

Figure I - "On-off" chart of patients with complex motor fluctuations in response to oral levodopa therapy and during the day of intravenous lisuride infusion.

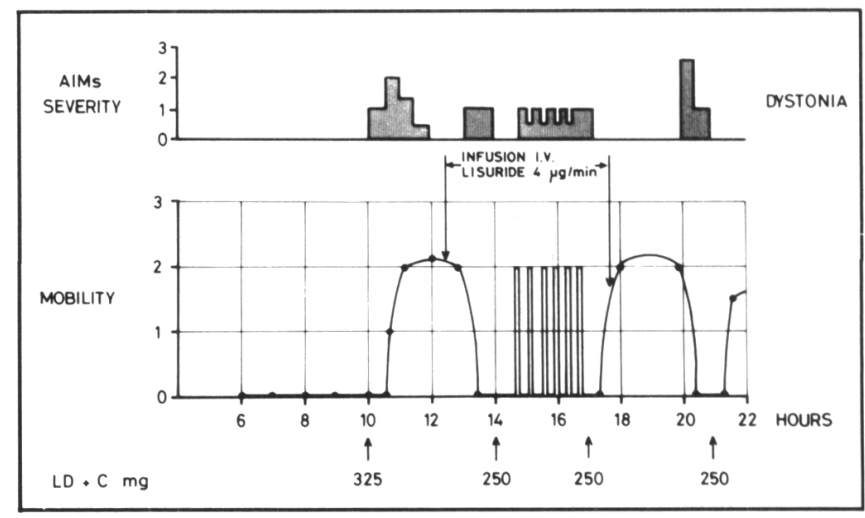

Figure 2 - Intravenous infusion of lisuride at a high rate produced no positive effect on mobility and "off' period dystonia in a patient with ' wearing off' "plus drug resistant "off period" 
patients treated for more than three months (mean $=10.2$ months, maximum 24 months) the average daily dose of lisuride was $2.60 \mathrm{mg}(0.5-4.5)$, generally using a constant infusion rate $($ mean $=114.8 \mathrm{ug} / \mathrm{h})$. The levodopa dose was reduced from a mean of $878 \mathrm{mg} /$ day to $558 \mathrm{mg} /$ day ( $37 \%$ decrease). Most patients showed considerable improvement in motor capacity after reaching the optimum regimen of subcutaneous lisuride and oral levodopa plus DDI (Figure 3). Perhaps the most dramatic effect was that periods of total immobility disappeared. Thus, although motor capacity was not completely stable throughout the day, patients could be independent most of the time because "off" periods were considerably less severe (Table 1). Another notable effect of lisuride infusion was to improve night and early morning mobility in all patients. Diphasic dyskinesia and "off" period dystonia were abolished or greatly reduced in all patients. Patients with "benefit of dose" dyskinesias showed variable response to lisuride infusion. ${ }^{26}$ Three patients with "benefit of dose" dyskinesias showed a significant improvement, but dyskinesias became a difficult management problem in about $20 \%$ of patients treated chronically.

All patients took domperidone $10 \mathrm{mg}$ tds (po) a few days before and during the initial weeks of the infusion to prevent nausea and vomiting. Oral daily treatment with levodopa plus DDI had to be maintained, albeit at a lower dose, in most patients and adjusted subsequently according to the clinical response.

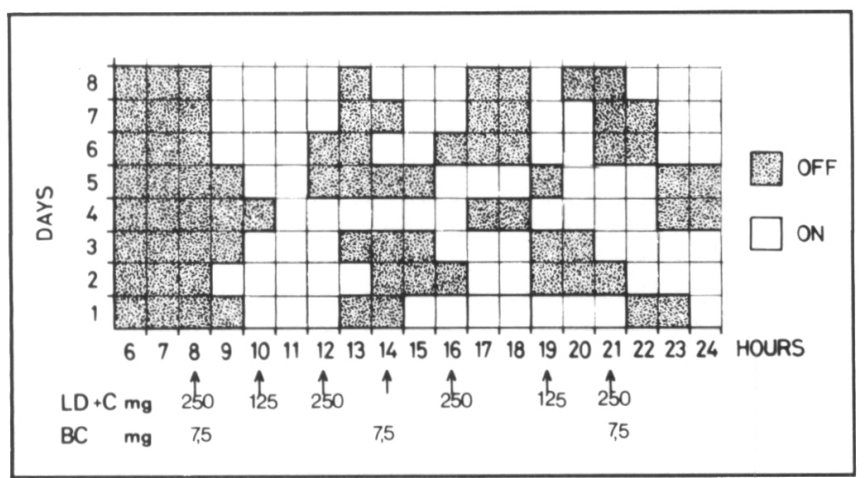

A

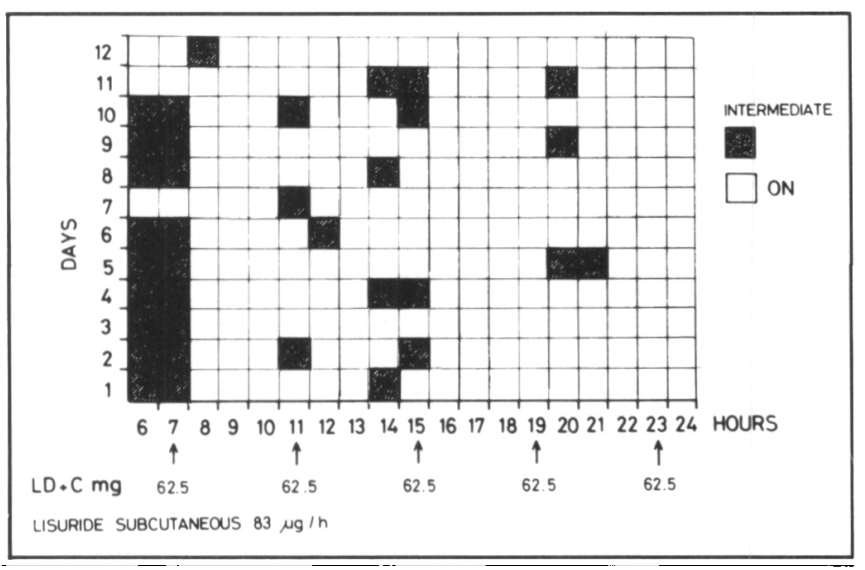

B

Figure 3 - "On-off' chart of a patient with complex "on-off' fluctuations before $(A)$ and after $(B)$ starting lisuride subcutaneous infusion. "Off" periods practically disappeared under subcutaneous lisuride plus oral levodopa, the patient only showing minor episodes of reduced motor capacity.
Subcutaneous nodules developed at the injection sites in all patients. Nodules of sufficient dimension and with inflammatory component interfering with absorption of lisuride were present in five patients. Physical and psychological adaptations to wearing a pump and the procedure of changing the needle in the abdomen has been excellent in most cases. Psychiatric complications of sufficient intensity to temporarily stop infusion were seen in nine patients while permanent withdrawal occurred in five patients.

The effect of lisuride infusion on motor fluctuations has been confirmed by other investigators. ${ }^{27,28}$ Problems which limit the efficiency of lisuride infusion and its generalized application include psychiatric complications in the first place ${ }^{28}$ but also development of subcutaneous nodules, variations in lisuride's plasma levels throughout the day and necessity of levodopa treatment (po) which may condition the response of postsynaptic dopaminergic receptors. ${ }^{29}$

\section{Apomorphine}

The use of apomorphine in Parkinson's disease was limited until recently by the severity and high incidence of side-effects such as nausea, vomiting, hypotension, sweating and malaise. ${ }^{30}$ At present, pre-treatment with domperidone (10-20 mg tds) during several days or its acute administration ( $20 \mathrm{mg}$ IV) a few minutes before apomorphine produces a marked attenuation of adverse effects. A single apomorphine bolus (IV) of 1-3 mg or $15-40$ micrograms $/ \mathrm{kg}$ is usually sufficient to obtain full motor capacity ("on") in patients with "on-off" phenomenon.

Continuous intravenous administration of apomorphine is started with a bolus of apomorphine which generally turns the patient "on", and continued with a constant infusion rate unless deterioration in motor function supervenes. The infusion rate ( $\mathrm{mg} /$ hour) is calculated as two to three times the minimal amount which given as a bolus turned the patient "on". Domperidone ( $20 \mathrm{mg} / \mathrm{IV}$ ) is given 20 minutes before starting the infusion in a bolus and repeated every 90-120 minutes according to tolerance. Apomorphine infusions may keep a patient completely mobile for many hours, but such a response is not uniform in all patients. Perhaps this is due to the development of hyposensitivity during the infusions. ${ }^{31}$ It is therefore our preliminary impression that apomorphine may not be a practical drug for continuous dopaminergic stimulation in ambulatory patients. However apomorphine infusions may serve as a very useful tool to investigate dopaminergic function in patients with motor fluctuations.

Table 1: Summary of change in mobility in 26 patients chronically treated with subcutaneous lisuride infusion $(X=9.6$ months $)$

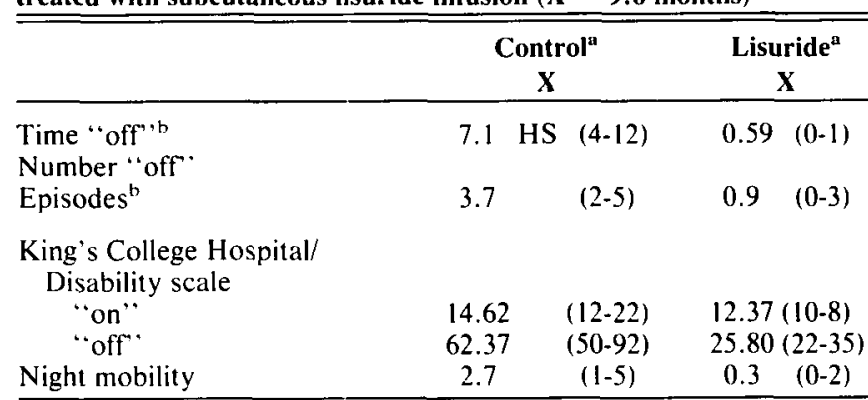

${ }^{a}$ Mean and range

b Estimated over a 12 hour observation period 


\section{5 (+)-4-Propyl-9-hydroxynaphthoxazine ( + -PHNO)}

$(+)$-PNHO is a new dopamine agonist, structurally different from other morphine or ergot derivatives currently used in Parkinson's disease. Both "in vitro" and "in vivo" experiments indicate that PHNO acts directly on post-synaptic dopamine receptors. $(++)$ PHNO is probably a selective D-2 dopamine agonist with some affinity for 5HT-1 and alpha- 2 receptors. Two clinical trials, using (+)-PHNO by oral route, ${ }^{32,33}$ and experimental studies in MPTP-treated marmosets ${ }^{34}$ have confirmed that the drug is effective in reversing acutely the motor disability of Parkinson's disease.

$(+) \mathrm{PHNO}$ is a suitable candidate for continuous transdermal delivery, but clinical studies have not yet been initiated.

\begin{tabular}{l}
\hline Table 2: Continuous DA stimulation in Parkinson's disease \\
\hline \hline 1. ADMINISTRATION ROUTE: \\
- Intravenous \\
- Subcutaneous \\
- Transcutaneous \\
- Intraventricular \\
2. IDEAL DRUG: \\
- Monotherapy \\
- Short plasma half-life \\
- Preferential action on DA striatal receptors \\
3. CLINICAL INDICATIONS: \\
- On-off phenomenon \\
- Wearing-off, night immobility \\
- "Square wave dyskinesias"" \\
- Young-onset parkinsonians
\end{tabular}

\section{Conclusions}

The "on-off" phenomenon is one of the major problems associated with long-term levodopa therapy. Parenteral delivery of antiparkinsonian drugs avoids most of the kinetic problems encountered after oral administration.

Continuous dopaminergic stimulation appears to be an efficient therapeutic approach for the treatment of motor fluctuations. None of the drugs presently available are capable of completely eradicating complex "on-off" fluctuations. Further research is required to define the best route of administration and to test newer dopaminomimetic drugs (Table 2). The mode of drug administration used may also be very relevant. Thus, investigations will have to compare the different efficacy of pulsatile, intermittent, continuous but variable infusion rates or constant delivery of dopaminergic drugs. In addition continuous dopaminergic stimulation may become an early therapeutic tool for the prevention of motor complications associated with standard levodopa therapy.

\section{ACKNOWLEDGEMENT}

The authors are grateful to Mrs. Jacqueline Oehling for kindly typing and preparing the manuscript and to Mrs. Carol Elders for reviewing the text.

\section{REFERENCES}

1. Marsden CD, Parkes JD. "On-off" effects in patients with Parkinson's disease in chronic levodopa therapy. Lancet 1976; I: 292-296.

2. Lewitt PA, Chase TN. "On-off" effects; the new challenge in parkinsonism. Trends Neurosci 1983; 6: 1-4.

3. Fahn S. Fluctuations of disability in Parkinson's disease: Pathophysiology. In: Movement Disorders, ed. Marsden CD and Fahn S. Butterworth, London 1982; 123-145.

4. Marsden CD, Parkes JD, Quinn N. Fluctuations of disability in Parkinson's disease: Pathophysiological aspects. $I n$ : Movement Disorders. Marsden CD and Fahn S, eds. Butterworth, London 1982; 96-122.

5. Fahn S. Episodic failure of absorption of L-dopa: A factor in the control of clinical fluctuations in the treatment of parkinsonism. Neurology 1977; 27 (suppl 2): 390.

6. Melamed E. Initiation of levodopa therapy in parkinsonian patients should be delayed until the advanced stages of the disease. Arch of Neurology 1986; 43: 402-405.

7. Schwab RS, Amador LV, Lettvin JY. Apomorphine in Parkinson's disease. Trans Amer Neurol Assoc 1951; 76: 2512-2513.

8. Nutt JG, Fellman JH. Pharmacokinetics of levodopa. Clin Neuropharm 1984; 7: 35-50.

9. Gervas JJ, Muradas V, Bazan E, et al. Effects of 3-OM-dopa on monamine metabolism in rat brain. Neurology (Cleveland) 1983; 33: $278-282$.

10. Reches A, Nuelke LR, Fahn S. 3-0-Methyldopa inhibits rotations induced by levodopa in rats after unilateral destruction of the nigrostriatal pathway. Neurology (NY) 1983; 32: 887-888.

11. Sthal S. Applications of new drug delivery technologies to Parkinson's disease and dopaminergic agents. J Neural Trans (in press).

12. Obeso JA, Sthal $\mathrm{S}$. New routes of administration for antiparkinsonian therapy. "Drugs for the treatment of Parkinson's disease". Calne DB, Springer-Verlag, Berlin (in press).

13. Shoulson I, Glaubiger GA, Chase TN. On-off response: Clinical and biochemical correlations during oral and intravenous levodopa administration in parkinsonian patients. Neurology 1975: 25: 1144-1148

14. Rosin AJ, Devereux D, Calne DB. Parkinsonism with "on-off" phenomena-intravenous treatment with levodopa after major abdominal surgery. Arch Neurol 1979; 36: 32-34.

15. Quinn NP, Parkes JD, Marsden CD. Control of "on-off" phenomenon by continuous intravenous infusion of levodopa. Neurology 1984; 34: 1131-1136.

16. Hardie RJ, Lees AJ, Stern GM. On-off fluctuations in Parkinson's disease: A clinical and neuropharmacological study. Brain 1984; 107: 487-506.

17. Nutt JG, Woodward WR, Hammerstad JP, et al. The "on-off" phenomenon in Parkinson's disease. New Eng J Med 1984; 310 : 483-488.

18. Marion MH, Stocchi F, Quinn NP, et al. Repeated levodopa infusions in fluctuating Parkinson's disease: Clinical and pharmacokinetic data. Clin Neuropharm 1986; 9: 165-181.

19. Chase TN, Mouradian MM, Fabbrini G, et al. Pathogenetic studies of motor fluctuations in Parkinson's disease. J Neurol Trans (in press).

20. Luquin MR, Obeso JA, Martinez Lage JM, et al. Levodopa and 3-0-Methyldopa plasma levels in Parkinson's disease: Patients with clinical fluctuations versus smooth responders. Neurology 1986; 36 (supp 1): 244.

21. Cooper DR, Marrel C, Testa B, et al. L-Dopa Methyl Ester: A candidate for chronic systemic delivery of L-Dopa in Parkinson's disease. Clin Neuropharm 1984; 7: 88-98.

22. Obeso JA, Martinez Lage JM, Luqwuin MR. Lisuride infusion for Parkinson's disease. Ann Neurol 1983; 14: 134.

23. Obeso JA, Luquin MR, Martinez Lage JM. Intravenous lisuride corrects motor oscillations in Parkinson's disease. Ann Neurol 1986a; 19: 31-35.

24. Luquin MR, Obeso JA, Martinez Lage JM, et al. Parenteral administration of lisuride in Parkinson's disease. Adv Neurol 1987: 45.

25. Obeso JA, Luquin MR, Martinez Lage JM. Lisuride infusion pump: A device for the treatment of motor fluctuations in Parkinson's disease. Lancet 1986b; I: 467-470. 
26. Obeso JA, Luquin MR, Vaamonde J, et al. Continuous subcutaneous administration of lisuride in the treatment of complex motor fluctuations in Parkinson's disease. J Neural Trans (in press).

27. Critchley P, Grandas F, Quinn N, et al. Continuous subcutaneous lisuride infusions in Parkinson's disease. J Neural Trans (in press).

28. Ruggieri S, Stocchi F, Agnoli A. Lisuride infusion pump for Parkinson's disease. Lancet 1986; 1I: 348-349.

29. Vaamonde J, Obeso JA, Luquin R. Increased levodopa consumption reduces motor response to apomorphine in Parkinson's disease. Neurology 1987; (suppl 1): 37.

30. Cotzias GC, Mena I, Papavasilious PS. Overview of present treatment of parkinsonism with levodopa. Adv Neurol 1973;2: 265-277.
31. Winkler JD, Weiss B. Reversal of supersensitivity apomorphine induced rotational behaviour in mice by continuous exposure to apomorphine. J Phar Exp Therap 1986; 238: 242-247.

32. Stoessl AJ, Mak E, Calne DB. (+)-4-propyl-9-hydroxynaphthoxazine (PHNO), a new dopaminomimetic, in treatment of parkinsonism. Lancet 1985; 2: 1330-1331.

33. Grandas Perez F, Jenner J, Nomoto M, et al. (+)-4-propyl-9hydroxynaphthoxazine in Parkinson's disease. Lancet 1986; 1: 906.

34. Coleman RJ, Grandas Perez F, Quinn N, et al 4-propyl-9-hydroxynaphthoxazine in Parkinson's disease and MPTP models (in press). 